\title{
Is it time to relax nephrogenic systemic fibrosis guidelines and safely offer magnetic resonance imaging to more patients?
}

\author{
Saif Al-Chalabi, Constantina Chrysochou, Philip A. Kalra \\ Department of Renal Medicine, Salford Royal NHS Foundation Trust, Salford, UK \\ Correspondence to: Saif Al-Chalabi. Department of Renal Medicine, Salford Royal NHS Foundation Trust, Salford, UK. Email: alchalabi01@gmail.com. \\ Comment on: Attari H, Cao Y, Elmholdt TR, et al. A Systematic Review of 639 Patients with Biopsy-confirmed Nephrogenic Systemic Fibrosis. \\ Radiology 2019;292:376-86.
}

Submitted Oct 02, 2019. Accepted for publication Oct 22, 2019.

doi: 10.21037 /qims.2019.10.11

View this article at: http://dx.doi.org/10.21037/qims.2019.10.11

Nephrogenic systemic fibrosis (NSF) is a potentially fatal fibrosing disorder that involves the skin and other internal organs. It is almost always associated with an advanced degree of chronic kidney disease (CKD) or acute kidney injury (AKI). Advances in medical knowledge underpinned some understanding of the pathophysiology and aetiology of this condition which then led to the emergence of strict guidelines for the use of gadolinium (Gd) enhanced MRI scans (Gd-MRI). In a recent issue of Radiology, Attari et al. present a systematic review of 639 biopsy confirmed cases of NSF derived from a thorough literature search which included 173 published articles (1). They present valuable information about the predisposing level of kidney disease and the type of scan of patients who developed NSF. Notably, almost all of these cases were administered primarily non-ionic linear Gd-based contrast agents (GBCA), and at high doses $(>0.1 \mathrm{mmol} / \mathrm{kg})$.

To fully understand this disorder and the current guidelines that have been developed to prevent it, a brief history of NSF is essential. In 1997, several reports were published about a skin disorder that resembled scleromyxedema. It was first named nephrogenic fibrosing dermopathy which then changed to NSF after a series of clinical observations indicated that disease features extended beyond the skin into internal organs. The cause of NSF remained unknown for almost a decade. A strong link was subsequently found with GBCA enhanced MRI (GBCAMRI) scans after a landmark study from Denmark identified this relationship in 13 confirmed cases of NSF (2). All of these patients had been exposed to GBCA between 2-75 days before showing signs and symptoms of the disease. Seven out of 13 patients were chronic haemodialysis patients, one received peritoneal dialysis and 5 had CKD stage 5 . Subsequently, a surge of cases was published, all linking GdMRI to NSF, the majority of these cases having received nonionic linear GBCA administered at high doses (3-5).

Of the 639 cases included in Attari et al.'s systematic review sufficient data about the degree of kidney impairment was found only in 322 patients. Of these, $278(86.3 \%)$ were receiving dialysis. Only 3 patients had an estimated glomerular filtration rate (eGFR) above $30 \mathrm{~mL} / \mathrm{min} / 1.73 \mathrm{~m}^{2}$ but all of these patients had AKI thereby making the eGFR estimation inaccurate (1).

The exact pathogenesis of GBCA related NSF remains unclear. In patients with advanced kidney disease, the clearance of GBCA is significantly slower when compared to normal subjects as they are predominantly excreted by the kidneys. A study showed that people receiving dialysis may take up to 40-fold longer to clear GBCA when compared to volunteers with normal kidney function (6). The pathogenetic theory concentrates on the possibility that during this extended period of bioavailability, transmetallation (transfer of ligands from one metal to another) with endogenous ions has a greater opportunity to occur. Also of relevance here is the acidic environment in patients with advanced kidney disease, as this could allow easier dissociation of Gd ions (7-9).

All available Gd contrast agents are chelates that contain 
the Gd ion (Gd3+). GBCA can be categorized according to structure into cyclical and linear agents; the former has superior characteristics of binding to $\mathrm{Gd} 3+$ to allow more efficient clearance but also limited release of free Gd. Another classification considers the charge of the GBCA, with a greater likelihood of transmetallation with non-ionic molecules compared to ionic molecules (10).

Recent investigations have suggested that the responsible cell in the pathogenesis of NSF is a cell involved in wound healing and tissue remodeling, the circulating fibroblast (CF) (11), which is distinct from other dermal fibroblasts. It has a CD34/procollagen dual-positive profile and is blood borne, which provides an explanation for the systemic features of NSF (12). These cells can target areas of cell injury where they can differentiate and cause scarring along with activation of local cellular immunity (13). Wermuth et al. showed that GBCA has a direct effect on inducing activation of monocytes resulting in gene activation and release of cytokines and other chemical compounds. These, in turn, can activate fibroblasts to induce tissue changes in NSF (14).

Attari et al. found that there were 525 cases of GBCArelated NSF. Only one of these NSF cases was associated with the use of a cyclical Gd preparation used alone. The patient was a 59-year-old male with an eGFR of $34 \mathrm{~mL} / \mathrm{min} / 1.73 \mathrm{~m}^{2}$ (calculated by MDRD) who had an MRI in 2008 and subsequent biopsy proven NSF (15). Unfortunately, no documentation of the patient's weight is available in the published article, and it is possible that the MDRD eGFR may have been inaccurate.

In 2008, and after the surge of NSF reported cases, new guidelines emerged around the safety of GBCA use in MRI scans, and some of these have subsequently been modified. UK guidelines from the Royal College of Radiologists (RCR) are stricter than the American counterpart. Current RCR guidelines advise administering GBCA for people with moderate CKD (eGFR 30-59 $\mathrm{mL} / \mathrm{min}$ ) only when it is "necessary". For patients with advanced CKD (eGFR $<30 \mathrm{~mL} / \mathrm{min}$ ), it recommends using low-risk cyclical GBCA agents (gadobutrol, gadoterate meglumine or gadoteridol) (16). However, the American College of Radiologists guidelines recommend no precautions for people with an eGFR above $30 \mathrm{~mL} / \mathrm{min} / 1.73 \mathrm{~m}^{2}$. In addition, the administration of low-risk GBCA (e.g., cyclical GBCA agents, referred to as group II) does not require informed consent regardless of kidney function and the state of dialysis as "the risk is very low if any" (17).

The very low/negligible risk of NSF in CKD patients without end-stage kidney disease, and with use of cyclical GBCA agents, was supported by our findings reported in 2009 (18). A total of 2,053 patients underwent 2,278 GBCA-MRI scans in two large renal centres in the United Kingdom (Salford Royal and Hammersmith hospitals); 491 (23.9\%) patients had stage 4 and 117 (5.7\%) had predialysis stage 5 CKD. No cases of NSF were identified during an average follow-up period of 28.6 (18.2) months. This study was undertaken after our critical review of the available literature in 2009 which combined data from the multicentre Angioplasty and Stenting for Renal Artery Lesions (ASTRAL) study in which 347 patients underwent GBCA-MRI, 32\% of these had CKD stages 4/5 (19). By extrapolation, 1/1,735 patients screened for the ASTRAL trial developed NSF, giving a crude incidence rate of $0.06 \%$. We identified that there was a positive reporting bias in the literature and recommended that patients with CKD stage 4 could safely undergo GBCA-MRA, albeit using a minimal dose of a macrocyclic agent and avoiding repeat doses.

The crucial finding of Attari et al.'s systematic review is that since 2008 there was a dramatic decline in NSF cases which in large part has undoubtedly been due to adherence to the strict guidelines adopted by major radiology societies around the world. In fact, only eight reported cases of NSF were identified since 2008. The details of these cases are shown in Table 1. Six of these subjects were receiving dialysis during the time of exposure to GBCA. One patient had bilateral nephrectomies with no dialysis information (but must have been treated with dialysis) and another had an unspecified degree of CKD. Attari et al. also presented follow up data for 341 of the NSF patients in the review; 12 patients were cured of the condition and 72 patients partially improved including one during pregnancy. Interestingly, among these 84 patients reported as cured or improved NSF, this only occurred after renal function restoration in $41 \%$ of the patients.

In summary, the guidelines implemented in 2008 have radically reduced the worldwide incidence of NSF. The rate of NSF per million exposures to GBCA was 2.07 (95\% CI: 1.90-2.26) up until 2008 whereas this figure is estimated to be 0.028 per million exposures (95\% CI: 0.012-0.060) since $2008(\mathrm{P}<0.001)$, a $>70$-fold reduction. The question now raised is whether the limitations imposed by the guidelines are too strict, likely denying many people a crucial diagnostic investigation. Attari et al.'s systematic review provides confidence that people who are not in AKI or have concomitant illness, and have a stable eGFR above $15 \mathrm{~mL} / \mathrm{min} / 1.73 \mathrm{~m}^{2}$, can safely have an MRI with GBCA. 
Table 1 Biopsy-proven NSF cases after 2008

\begin{tabular}{|c|c|c|c|c|c|}
\hline $\begin{array}{l}\text { Study authors } \\
\text { (reference) }\end{array}$ & CKD degree & Primary renal disease & Gad used (group) & Age (years) & Sex \\
\hline Chuang et al. (20) & Dialysis (not specified) & Membranous nephropathy & Gadoversetamide (group I) & 61 & Male \\
\hline Lohani et al. (22) & eGFR $23 \mathrm{~mL} / \mathrm{min} / 1.73 \mathrm{~m}^{2}$ & Data not available & Unknown gad & 57 & Female \\
\hline \multirow{2}{*}{ Kreuter et al. (23) } & Dialysis (not specified) & Data not available & Unknown gad & 54 & Female \\
\hline & $\begin{array}{l}\text { Bilateral nephrectomies } \\
\text { (must be on dialysis) }\end{array}$ & Data not available & Unknown gad & 28 & Female \\
\hline Thomson et al. (24) & Haemodialysis & Data not available & $\begin{array}{l}\text { Multiple exposures with at least one } \\
\text { dose of gadodiamide (group I) }\end{array}$ & 67 & Male \\
\hline
\end{tabular}

NSF, nephrogenic systemic fibrosis; CKD, chronic kidney disease; eGFR, estimated glomerular filtration rate; Gad, gadolinium.

People with eGFR less than $15 \mathrm{~mL} / \mathrm{min} / 1.73 \mathrm{~m}^{2}$ or those receiving dialysis should only have group 2 (low risk) GBCA to avoid the small but well-accepted risk of NSF.

\section{Acknowledgments}

None.

\section{Footnote}

Conflicts of Interest: The authors have no conflicts of interest to declare.

\section{References}

1. Attari H, Cao Y, Elmholdt TR, Zhao Y, Prince MR. A Systematic Review of 639 Patients with Biopsyconfirmed Nephrogenic Systemic Fibrosis. Radiology 2019;292:376-86.

2. Marckmann P, Skov L, Rossen K, Dupont A, Damholt MB, Heaf JG, Thomsen HS. Nephrogenic systemic fibrosis: suspected causative role of gadodiamide used for contrast-enhanced magnetic resonance imaging. J Am Soc Nephrol 2006;17:2359-62.

3. Cowper SE, Robin HS, Steinberg SM, Su LD, Gupta S, LeBoit PE. Scleromyxoedema-like cutaneous diseases in renal-dialysis patients. Lancet 2000;356:1000-1.

4. Moreno-Romero JA, Segura S, Mascaró JM Jr, Cowper SE, Julià M, Poch E, Botey A, Herrero C. Nephrogenic systemic fibrosis: a case series suggesting gadolinium as a possible aetiological factor. Br J Dermatol 2007;157:783-7.

5. Collidge TA, Thomson PC, Mark PB, Traynor JP, Jardine AG, Morris ST, Simpson K, Roditi GH. Gadoliniumenhanced MR imaging and nephrogenic systemic fibrosis: retrospective study of a renal replacement therapy cohort. Radiology 2007;245:168-75.

6. Joffe P, Thomsen HS, Meusel M. Pharmacokinetics of gadodiamide injection in patients with severe renal insufficiency and patients undergoing hemodialysis or continuous ambulatory peritoneal dialysis. Acad Radiol 1998;5:491-502.

7. Grobner T. Gadolinium-a specific trigger for the development of nephrogenic fibrosing dermopathy and nephrogenic systemic fibrosis Nephrol Dial Transplant 2006;21:1104-8.

8. Khurana A, Runge VM, Narayanan M, Greene JF Jr, Nickel AE. Nephrogenic systemic fibrosis: a review of 6 cases temporally related to gadodiamide injection (omniscan). Invest Radiol 2007;42:139-45.

9. Boyd AS, Zic JA, Abraham JL. Gadolinium deposition in nephrogenic fibrosing dermopathy. J Am Acad Dermatol 2007;56:27-30.

10. Desreux JF, Gilsoul D. Chemical synthesis of paramagnetic complexes. In: Thomsen H, Muller RN, Mattrey RF. editors. Trends in contrast media. Heidelberg: Springer, 2007:161-8.

11. Quan TE, Cowper SE, Bucala R. The role of circulating fibrocytes in fibrosis. Curr Rheumatol Rep 2006;8:145-50. 
12. Cowper SE, Bucala R, Leboit PE. Nephrogenic fibrosing dermopathy/nephrogenic systemic fibrosis--setting the record straight. Semin Arthritis Rheum 2006;35:208-10.

13. Cowper SE. Nephrogenic fibrosing dermopathy: the first 6 years. Curr Opin Rheumatol 2003;15:785-90.

14. Wermuth PJ, Del Galdo F, Jiménez SA. Induction of the expression of profibrotic cytokines and growth factors in normal human peripheral blood monocytes by gadolinium contrast agents. Arthritis Rheum 2009;60:1508-18.

15. Elmholdt TR, Jørgensen B, Ramsing M, Pedersen M, Olesen AB. Two cases of nephrogenic systemic fibrosis after exposure to the macrocyclic compound gadobutrol. NDT Plus 2010;3:285-7.

16. The Royal College of Radiologists. Guidance on gadolinium-based contrast agent administration to adult patient 2019. [cited 22 September 2019]. Available online: https://www.rcr.ac.uk/publication/guidance-gadoliniumbased-contrast-agent-administration-adult-patients

17. Acr.org. Contrast Manual 2019. [cited 22 September 2019]. Available online: https://www.acr.org/ClinicalResources/Contrast-Manual

18. Chrysochou C, Power A, Shurrab AE, Husain S, Moser S, Lay J, Salama AD, Kalra PA. Low risk for nephrogenic systemic fibrosis in nondialysis patients who have chronic kidney disease and are investigated with gadoliniumenhanced magnetic resonance imaging. Clin J Am Soc Nephrol 2010;5:484-9.

Cite this article as: Al-Chalabi S, Chrysochou C, Kalra PA. Is it time to relax nephrogenic systemic fibrosis guidelines and safely offer magnetic resonance imaging to more patients? Quant Imaging Med Surg 2019;9(11):1918-1921. doi: 10.21037/ qims.2019.10.11
19. Chrysochou C, Buckley DL, Dark P, Cowie A, Kalra PA. Gadolinium-enhanced magnetic resonance imaging for renovascular disease and nephrogenic systemic fibrosis: critical review of the literature and UK experience. J Magn Reson Imaging 2009;29:887-94.

20. Chuang K, Kaneshiro C, Betancourt J. Nephrogenic Systemic Fibrosis in a Patient With Multiple Inflammatory Disorders. Fed Pract 2018;35:40-3.

21. Fuah KW, Lim CTS. Erythema nodosum masking nephrogenic systemic fibrosis as initial skin manifestation. BMC Nephrol 2017;18:249.

22. Lohani S, Golenbiewski J, Swami A, Halalau A. A unique case of nephrogenic systemic fibrosis from gadolinium exposure in a patient with normal eGFR. BMJ Case Rep 2017. doi: 10.1136/bcr-2017-221016.

23. Kreuter A, Gambichler T, Weiner SM, Schieren G. Limited effects of UV-A1 phototherapy in 3 patients with nephrogenic systemic fibrosis. Arch Dermatol 2008;144:1527-9.

24. Thomson LK, Thomson PC, Kingsmore DB, Blessing K, Daly CD, Cowper SE, Roditi GH. Diagnosing nephrogenic systemic fibrosis in the post-FDA restriction era. J Magn Reson Imaging 2015;41:1268-71.

25. Mitkov M, Fosko S, Sluzevich J. Nephrogenic systemic fibrosis complicated by extensive dystrophic calcification. J Am Acad Dermatol 2018;79:AB203. 